\title{
Unrecognized myocardial infarction by echocardiography in relation to infarct characteristics as assessed by cardiovascular magnetic resonance imaging
}

\author{
Caroline Jaarsma ${ }^{1,2^{*}}$, Simon Schalla ${ }^{1,3}$, Emile C Cheriex ${ }^{1}$, Martijn Smulders ${ }^{1,3}$, Ivo M van Dongen ${ }^{1}$, \\ Patricia J Nelemans ${ }^{3,4}$, Joachim E Wildberger ${ }^{2,3}$, Harry J Crijns ${ }^{1,3}$, Sebastiaan C Bekkers ${ }^{1,3}$
}

From 15th Annual SCMR Scientific Sessions

Orlando, FL, USA. 2-5 February 2012

\section{Background}

Accurate recognition of myocardial infarction (MI) is important, because of the benefits of immediate and correct treatment. Despite being the method of choice, echocardiographic assessment of segmental wall motion abnormalities (SWMA) in MI can be difficult and depends on operator skills, experience, and image quality. The purpose of this study was to investigate the echocardiographic detection of SWMA by experienced echocardiographers in relation to underlying infarct characteristics as assessed with delayed-enhancement cardiovascular magnetic resonance imaging (DE-CMR).

\section{Methods}

In 88 consecutively and prospectively enrolled first STsegment elevation MI patients, 141 echocardiograms, performed 2 (interquartile range [IQR] 1-4) days (acute, $\mathrm{n}=61$ ) and 102 (IQR 92-112) days post-MI (chronic, $\mathrm{n}=80$ ), were available for evaluation. Pooled with echocardiograms of 36 healthy controls (absence of coronary artery disease and normal CMR), two experienced echocardiographers, who were blinded to patient and DE-CMR data, randomly evaluated all 177 echocardiograms for SWMA. This was compared with infarct characteristics, as assessed with DE-CMR performed $104 \pm 11$ days post-MI.

\section{Results}

In the MI group, mean age was $59 \pm 11$ years and $74 \%$ were men vs. $43 \pm 12$ years and $56 \%$ men in healthy

${ }^{1}$ Cardiology, Maastricht University Medical Center, Maastricht, Netherlands Full list of author information is available at the end of the article controls. The infarct-related artery (IRA) was the LAD, LCx and RCA in $31 \%, 12 \%$, and $57 \%$ of patients, respectively. All patients showed hyperenhancement on DECMR matching the IRA territory. The median infarct size was $11 \%$ (IQR 5-19) with a mean infarct transmurality of $57 \pm 16 \%$. The sensitivity of echocardiography to detect SWMA was $80.3 \%$ in the acute, and $65.0 \%$ in the chronic phase; the specificity was $80.6 \%$. In patients with unrecognized MI, infarcts were smaller (6\% [IQR 3-12] vs. $15 \%$ [IQR 9-23], p<0.001, Figure 1) and less transmural ( $50 \pm 14 \%$ vs. $61 \pm 15 \%, \mathrm{p}<0.001$, Figure 2$)$, left ventricular ejection fraction (LVEF) was higher $(59 \pm 5 \%$ vs. $46 \pm 8 \%, \mathrm{p}<0.001)$, and MI localization was more often non-anterior than anterior $(83 \%$ vs. $63 \%, \mathrm{p}<0.05)$. The strongest determinants of echocardiographic recognition of acute MI were LVEF (odds ratio per unit increase [OR] 0.77 (95\% confidence interval [CI] 0.64-0.92), $\mathrm{p}<0.01$ ), and LVEF and infarct size of chronic MI (OR 0.63 [95\%CI $0.49-0.81], \mathrm{p}<0.001$ and OR 1.20 [95\%CI 1.00-1.45], $\mathrm{p}=0.06$, respectively). Segmental analysis showed a significant increase in SWMA with increasing infarct transmurality, both in acute as well as chronic MI $(\mathrm{p}<0.001)$.

\section{Conclusions}

The sensitivity of echocardiography to detect MI was higher in acute than chronic infarctions. Unrecognized MI were smaller, less transmural, more often located non-anterior and related to a higher LVEF.

\section{Funding}

None.

(c) 2012 Jaarsma et al; licensee BioMed Central Ltd. This is an open access article distributed under the terms of the Creative Commons 

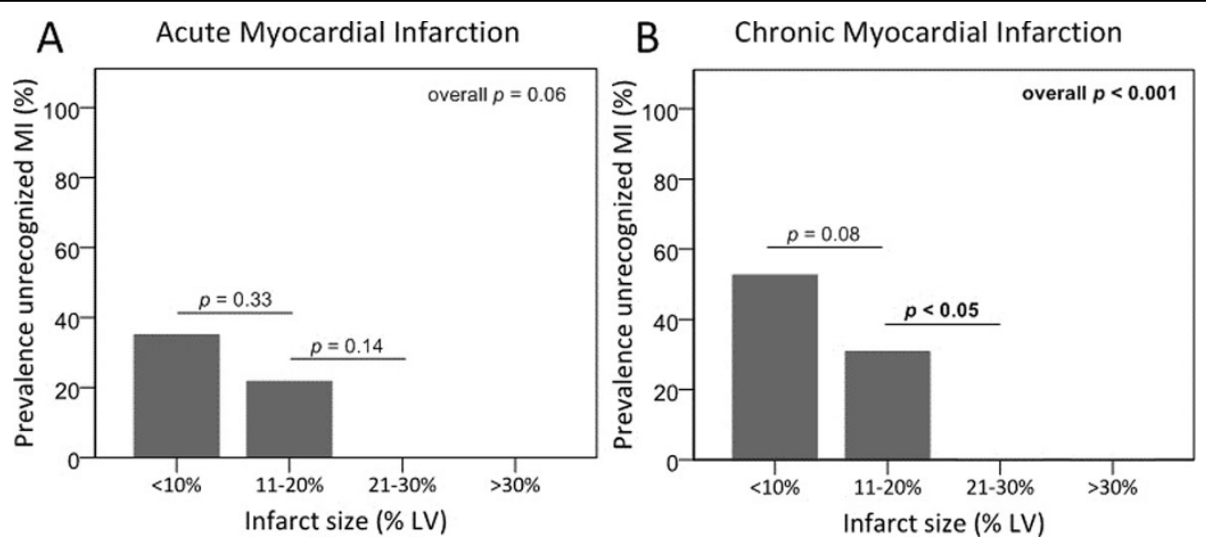

Figure 1 Unrecognized myocardial infarction in relation to infarct size.
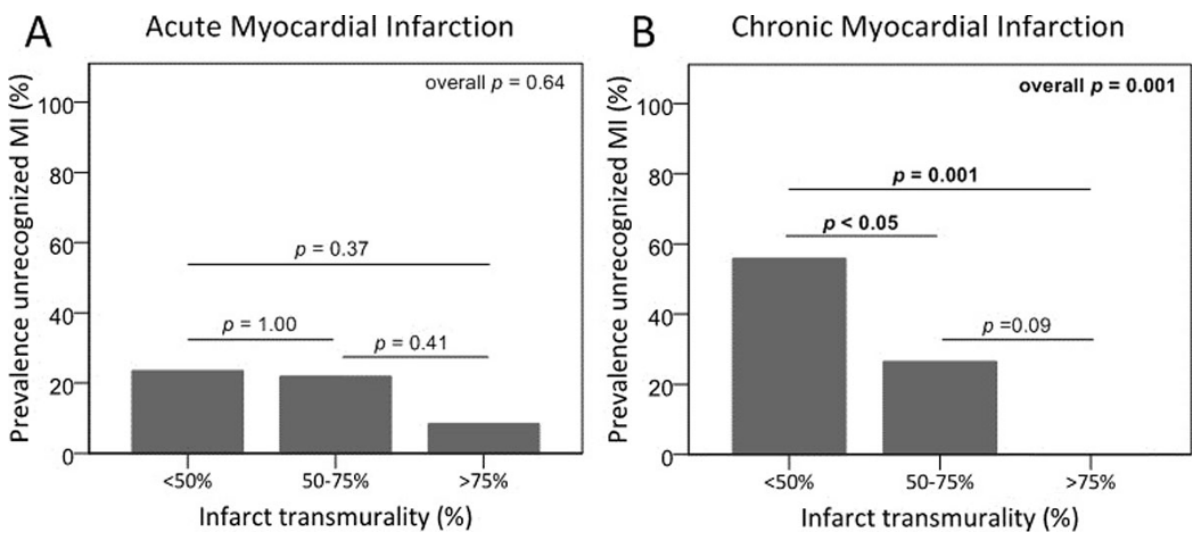

Figure 2 Unrecognized myocardial infarction in relation to infarct transmurality.

\section{Author details}

${ }^{1}$ Cardiology, Maastricht University Medical Center, Maastricht, Netherlands. ${ }^{2}$ Radiology, Maastricht University Medical Center, Maastricht, Netherlands.

${ }^{3}$ Cardiovascular Research Institute Maastricht, Maastricht University,

Maastricht, Netherlands. ${ }^{4}$ Epidemiology, Maastricht University, Maastricht, Netherlands.

Published: 1 February 2012

doi:10.1186/1532-429X-14-S1-036

Cite this article as: Jaarsma et al:: Unrecognized myocardial infarction by echocardiography in relation to infarct characteristics as assessed by cardiovascular magnetic resonance imaging. Journal of Cardiovascular Magnetic Resonance 2012 14(Suppl 1):O36.

\section{Submit your next manuscript to BioMed Central and take full advantage of:}

- Convenient online submission

- Thorough peer review

- No space constraints or color figure charges

- Immediate publication on acceptance

- Inclusion in PubMed, CAS, Scopus and Google Scholar

- Research which is freely available for redistribution

Submit your manuscript at www.biomedcentral.com/submit 